\title{
A POSSIBILIDADE DE DETERMINAÇÃO DE SEQUESTRO DE VERBAS COMO GARANTIA DE CUMPRIMENTO DE DECISÃO JUDICIAL QUE COMPELE O ENTE PÚBLICO AO FORNECIMENTO DE MEDICAMENTOS
}

\author{
THE POSSIBILITY OF AN INJUNCTION \\ FOR FUNDS AS A GUARANTEE FOR THE \\ ENFORCEMENT OF A COURT'S JUDGEMENT \\ COMPELLING THE GOVERNMENT \\ TO PROVIDE MEDICATION
}

\section{Marina Michels Ouriques Machado ${ }^{1}$}

Resumo: Para assegurar o direito à saúde, por meio da dispensação de medicamentos de forma gratuita pelo Sistema Único de Saúde (SUS), muitas vezes o cidadão precisa buscar a intervenção do Poder Judiciário, tendo em vista que as políticas públicas existentes nem sempre são aptas a cumprir o previsto no art. 196 da Constituição da República. Diante de tal realidade, busca-se verificar se é possível ao magistrado determinar a medida de sequestro de verbas públicas em caso de descumprimento de decisão que compele o Poder Público ao fornecimento de medicamentos.

Palavras-chave: Direito à saúde. Sequestro de verbas. Cumprimento. Ordem judicial. Medicamentos.
Astract: In order to seek for the right of health, by way of the provision of free medications performed by the Brazilian Free Health Care System (Sistema Único de Saúde - SUS), many persons must file a complaint to the judiciary, due to the fact that the existing public policies have not always been sufficient to provide as stated under art. 196 of the Brazilian Constitution. In light of these facts, the article seeks to verify whether it is possible for a judge to determine the amount of funds to be taken from the government in the case of the disobedience of a judgement that compelled the governmental authority to the supply of medications.

Keywords: Right of health. Injunction for funds. Enforcement. Injunction. Medications..

1 Especialista em Direito Aplicado e em Direito Público pela FURB, em convênio com a Escola Superior da Magistratura do Estado de Santa Catarina. Bacharel em Direito pela Universidade do Planalto Catarinense (UNIPLAC). Residente Judicial no Tribunal de Justiça do Estado de Santa Catarina (TJSC). E-mail: marinamomachado@gmail.com 


\section{INTRODUÇÃO}

O presente artigo tem como objetivo analisar a viabilidade de determinação da medida assecuratória de sequestro de verbas nos casos em que o Poder Público descumpre ordem judicial que, em sede de ação cominatória, o obriga ao fornecimento de fármacos pleiteados por particular.

Para tanto, faz-se breve incursão histórica sobre a previsão constitucional do direito à saúde, bem como à sua classificação e aplicabilidade. Posteriormente, aborda-se a possibilidade de ingresso em juízo para postular a concessão de medicamento negado pela Administração Pública. Discorre-se ainda sobre os poderes conferidos ao juiz no processo civil e, ao final, sobre a possibilidade de determinação do sequestro de valores para conferir efetividade a provimento judicial que compele o ente público à concessão de medicamento, tema cuja repercussão geral foi reconhecida pelo Supremo Tribunal Federal quando do julgamento do Recurso Extraordinário n. 607582 (Tema n. 289) e que aguarda manifestação da Corte.

\section{O DIREITO CONSTITUCIONAL À SAÚDE}

O direito à saúde encontra previsão expressa no art. 196 da Constituição da República. Todavia, faz-se necessário destacar que tal inserção é relativamente recente no ordenamento jurídico brasileiro, tendo em vista que sua inclusão no rol dos direitos fundamentais decorreu da grande repercussão e dimensão política alcançada por movimentos sociais ocorridos na década de 1970, além das tendências constitucionais voltadas ao aperfeiçoamento do Estado Social.

Antes do advento da Carta Magna de 1988, a concepção social de saúde, em um primeiro momento, consistia em um "favor" do Estado, ou seja,

[...] a saúde seria uma benesse que poderia ser retirada ou restringida em qualquer momento, sem qualquer garantia 
para sua manutenção. Principalmente a partir da adoção de medidas curativas e campanhísticas que marcaram o período, a saúde foi alçada a assunto de Estado, porém, ainda assim, a sua exigibilidade pelos cidadãos restou submetida à discricionariedade do poder público. Não havia qualquer instrumento jurídico-legal que garantisse a universalidade deste direito, sendo concentrada no Estado a possibilidade e a discricionariedade de realizar ações de saúde em benefício de uns em detrimento de outros, inclusive de forma autoritária, a exemplo do que se desenvolveu no âmbito da Revolta da Vacina de 1904. (ASENSI, 2013, p. 132).

A partir da Era Vargas, a ampliação dos direitos dos trabalhadores e a mercantilização dos serviços de saúde delinearam novos contornos de atuação política sobre o tema.

Posteriormente, na década de 1970, movimentos sociais de participação na saúde ganharam grande dimensão política. À época, entendeu-se que as ações voltadas à promoção da saúde deveriam ser formuladas conjuntamente pelo Estado e pela sociedade, por meio de espaços públicos de participação, tendo em vista que "[...] é a sociedade que vivencia o cotidiano das instituições de saúde e, portanto, conhece de forma mais próxima as suas mazelas e avanços [...]" (ASENSI, 2013, p. 134).

$\mathrm{O}$ aperfeiçoamento do Estado Social, aliado às tendências neoconstitucionalistas, impôs ao Poder Constituinte a observância e incorporação dos direitos e garantias fundamentais ao texto da Constituição de 1988, oportunizando "[...] a redemocratização do país após mais de vinte anos de ditadura militar [...]" (SARLET, 2015, p. 64).

Conforme lecionam Sarlet, Marinoni e Mitidiero (2012, p. 541-542), "[... ] foi apenas no texto promulgado em 05.10.1988, que os direitos sociais foram efetivamente positivados na condição de direitos fundamentais, pelo menos de acordo com expressa previsão do texto constitucional".

Tem-se, ademais, que a saúde 
[...] foi alçada à categoria de direito fundamental, cujo imperativo é a prestação positiva do Estado no sentido de concretizá-la e ampliá-la a todos os cidadãos. A universalização da saúde foi acompanhada de sua institucionalização normativa, o que possibilitou a cristalização de seus princípios, normas e diretrizes que seriam desenvolvidos nos anos seguintes, cuja expressão mais significativa foi a criação do Sistema Único de Saúde. Em seu art. 196, a Constituição estabelece que a saúde é um "direito de todos e dever do Estado" (Brasil, 1988), o que denota a pretensão universalizante deste direito. Em decorrência destas transformações, a saúde passa a ser caracterizada como direito fundamental e dever do Estado.

Neste contexto, atribuiu-se às ações e serviços de saúde o caráter de relevância pública, o que implica dizer que a alteração de tal preceito depende de amplo e rígido processo legislativo. Esta condição cristalizou sem precedentes a relevância jurídica, política e social da saúde no ordenamento jurídico brasileiro, sobretudo em função de sua forte associação com o princípio da dignidade da pessoa humana. $\mathrm{O}$ direito à saúde ainda se constituiu como cláusula pétrea no âmbito constitucional, uma vez que, em virtude de sua associação direta com o direito à vida, não pode ser excluído do resguardo que lhe foi alçado pela Carta Constitucional e pelas legislações posteriores. (ASENSI, 2013, p. 134-135, grifos do autor).

Vê-se, assim, que a previsão constitucional do direito à saúde e consequente obrigação do Estado em promovê-la de maneira universal mostram-se recentes no ordenamento jurídico Brasileiro, posto que sua positivação se deu apenas com a promulgação da Constituição da República de 1988, uma "Carta voltada para o aperfeiçoamento do Estado Social, que enfatiza os direitos fundamentais, dentre eles os direitos sociais e de democracia" (CANUT, 2013, p. 18).

Trata-se de direito fundamental de segunda geração, porque, segundo Mendes e Branco (2015, p. 137), pressupõe uma prestação positiva do Estado, a fim de estabelecer uma liberdade real e igualitária para todos e, consequentemente, atingir 
uma "justiça social".

Sarlet, Marinoni e Mitidiero (2012, p. 557) observam, quanto ao direito à saúde, que

[...] basta uma leitura superficial dos dispositivos pertinentes (arts. 196 a 200) para que se perceba que nos encontramos, em verdade, no que diz com a forma de positivação, tanto em face de norma definidora de direito (direito à saúde como direito subjetivo, de todos, portanto de titularidade universal), quanto diante de normas de cunho impositivo de deveres e tarefas, pois o art. 196 enuncia que a saúde é direito de todos e dever do Estado, além de impor aos poderes públicos uma série de tarefas nesta seara (como a de promover políticas sociais e econômicas que visem à redução do risco de doença e de outros agravos, além de estabelecer o acesso universal e igualitário às ações e prestações nesta esfera).

Nas palavras de Cunha Júnior (2016, p. 657),

[...] o direito social à saúde é tão fundamental, por estar mais diretamente ligado ao direito à vida, que nem precisava de reconhecimento explícito. Nada obstante, a Constituição brasileira dispôs que a saúde é um direito de todos e dever do Estado, garantido mediante políticas sociais e econômicas que visem à redução do risco de doença e de outros agravos e ao acesso universal e igualitário às ações e serviços para sua promoção, proteção e recuperação (art. 196). Assim constitui exigência inseparável de qualquer Estado que se preocupa com o valor vida humana, o reconhecimento de um direito subjetivo público à saúde. (grifos do autor).

Denota-se que, ao tratar da saúde, o legislador Constituinte originário estabeleceu, de um lado, um direito fundamental subjetivo, bem como, de outro, o dever estatal de garantir sua realização, que engloba a promoção, proteção e recuperação, sendo tal norma de eficácia plena, uma vez que

[...] dizer que a norma do art. 196, por tratar de um direito social, consubstancia-se tão somente em uma norma programática, incapaz de produzir efeitos, indicando diretrizes a serem observadas pelo poder público, significaria negar a força normativa da Constituição. (MENDES, 2015, p. 660). 
Sob esse enfoque, frisa-se que o Supremo Tribunal Federal, quando do julgamento do Recurso Extraordinário n. 241.630, de relatoria do Ministro Celso de Mello, manifestou-se no sentido de que

[...] o Poder Público, qualquer que seja a esfera institucional de sua atuação no plano da organização federativa brasileira, não pode mostrar-se indiferente ao problema da saúde da população, sob pena de incidir, ainda que por omissão, em censurável comportamento inconstitucional. $\mathrm{O}$ direito público subjetivo à saúde traduz bem jurídico constitucionalmente tutelado, por cuja integridade deve velar, de modo responsável, o Poder Público federal, estadual ou municipal, a quem incumbe formular - e implementar - políticas sociais e econômicas que visem garantir a plena consecução dos objetivos proclamados no art. 196. (BRASIL, 2001).

Vislumbra-se, portanto, o caráter dúplice conferido ao direito à saúde: trata-se, de um lado, de um dever da Administração Pública no que tange à formulação de políticas aptas a garantir os serviços necessários à sua promoção, proteção e recuperação, bem como, do outro, de um direito subjetivo do particular.

\section{DA JUDICIALIZAÇÃO DO DIREITO À SAÚDE}

Por se tratar de direito fundamental e, portanto, possuir aplicabilidade plena, a teor do que dispõe o art. $5^{\circ}, \S 1^{\circ}$, da Constituição da República ${ }^{2}$, a norma constitucional que disciplina a proteção à saúde está apta a produzir efeitos imediatos, independentemente de prévia regulamentação.

Por conta desse cenário - de aplicabilidade imediata às normas constitucionais relativas à proteção da saúde -, muito se fala, atualmente, na "judicialização do direito à saúde", sendo que o debate acerca da possibilidade de atuação do Poder Judiciário na concretização de direitos fundamentais (individuais ou sociais), chegou ao Supremo Tribunal Federal por meio do Pedido de

$\S 1^{\circ}$ As normas definidoras dos direitos e garantias fundamentais têm aplicação imediata. 
Suspensão de Tutela Antecipada n. 175, proposto pela União, de relatoria do Ministro Gilmar Mendes (BRASIL, 2010).

Em meio à discussão, sob o enfoque dos parâmetros a serem adotados para a solução judicial dos casos concretos que envolvem direito à saúde, tomando em conta a grande quantidade de processos envolvendo a matéria, bem como a complexidade das questões por eles tratadas, o relator convocou audiência pública com finalidade de ouvir especialistas na área de saúde pública.

Sobre os entendimentos delineados nos debates ocorridos, o relator consignou, em seu voto, que o maior impasse não diz respeito à interferência do Poder Judiciário na criação das políticas públicas destinadas em matéria de saúde "[...] pois o que ocorre, na quase totalidade dos casos, é apenas a determinação judicial do efetivo cumprimento de políticas públicas já existentes" (BRASIL, 2010, grifos do autor).

Dentre outras considerações, a conclusão do Ministro Gilmar Mendes, no tocante ao não fornecimento de determinada ação de saúde pelo Sistema Único de Saúde (SUS), foi no seguinte sentido:

[...] em geral, deverá ser privilegiado o tratamento fornecido pelo SUS em detrimento de opção diversa escolhida pelo paciente, sempre que não for comprovada a ineficácia ou a impropriedade da política de saúde existente. Essa conclusão não afasta, contudo, a possibilidade de o Poder Judiciário, ou de a própria Administração, decidir que medida diferente da custeada pelo SUS deve ser fornecida a determinada pessoa que, por razões específicas do seu organismo, comprove que o tratamento fornecido não é eficaz ao seu caso. Inclusive, como ressaltado pelo próprio Ministro da Saúde na Audiência Pública, há necessidade de revisão periódica dos protocolos existentes e de elaboração de novos protocolos. Assim, não se pode afirmar que os Protocolos Clínicos e Diretrizes Terapêuticas do SUS são inquestionáveis, o que permite sua contestação judicial. 
Situação diferente é aquela que envolve a inexistência de tratamento na rede pública. Nesses casos, é preciso diferenciar os tratamentos puramente experimentais dos novos tratamentos ainda não testados pelo Sistema de Saúde brasileiro [...]

Parece certo que a inexistência de Protocolo Clínico no SUS não pode significar violação ao princípio da integralidade do sistema, nem justificar a diferença entre as opções acessíveis aos usuários da rede pública e as disponíveis aos usuários da rede privada. Nesses casos, a omissão administrativa no tratamento de determinada patologia poderá ser objeto de impugnação judicial, tanto por ações individuais como coletivas. (BRASIL, 2010, grifos do autor).

Além disso, importa destacar que o ajuizamento de demanda visando compelir os entes públicos ao fornecimento de medicamentos não importa em ofensa ao Princípio da Separação de Poderes, previsto no art. $2^{\circ}$ da Constituição da República.

Cunha Júnior (2016, p. 465-466), ao comentar esse modelo de constituição fundamental do governo, citando Silva (1999, p. 114), assevera que

[...] atualmente, entre nós, a separação de Poderes se assenta na independência e na harmonia entre os órgãos do Poder Político. Isso significa que, não obstante a independência orgânica - no sentido de não haver entre eles qualquer relação de subordinação ou dependência no que tange ao exercício de suas funções -, a Constituição Federal instituiu um mecanismo de controle mútuo, onde há “interferências, que visam ao estabelecimento de um sistema de freios e contrapesos, à busca do equilíbrio necessário à realização do bem da coletividade e o indispensável para evitar o arbítrio e o desmando de um em detrimento de outro e especialmente dos governados".

Convém destacar, aliás, que o Supremo Tribunal Federal possui entendimento no sentido de que "[...] o Poder Judiciário pode, sem que fique configurada violação ao princípio da separação dos Poderes, determinar a implementação de políticas públicas nas questões relativas ao direito constitucional 
à saúde" (BRASIL, 2016).

Verifica-se, dessa forma, que inexiste óbice à propositura de demanda judicial visando resguardar o direito à saúde, norma constitucional de aplicabilidade imediata e eficácia plena.

\section{DA POSSIBILIDADE DE DETERMINAÇÃO DE SEQUESTRO DE VERBAS PÚBLICAS COMO GARANTIA DE CUMPRIMENTO DE DECISÃO JUDICIAL QUE COMPELE O ENTE PÚBLICO AO FORNECIMENTO DE MEDICAMENTOS}

Uma vez constatada a possibilidade de ajuizamento de ação visando compelir os entes federativos a fornecer medicamentos ou tratamentos médicos, impende ainda verificar a possibilidade de determinação e medidas que garantam efetividade ao provimento judicial emanado na demanda, para concretizar de maneira efetiva e imediata o direito fundamental à saúde da parte.

\subsection{Os poderes do juiz no processo civil}

Os poderes e deveres inerentes à figura do Estado-juiz encontram-se encartados nos arts. 139 e 141 da Lei n. 13.105, de 16 de março de 2015, que instituiu o novo Código de Processo Civil e, em regra, são aqueles concernentes à condução do processo e ao julgamento da causa.

Cintra, Dinamarco e Grinover (1984, p. 264), apontam que tais poderes, ou seja, aqueles que se desenvolvem no curso do processo, subdividem-se em poderes-meio, pelos quais se dá o simples andamento processual, atos ordinatórios e instrutórios, que se destinam à formação do convencimento do juiz e poderes-fim, que compreendem os atos decisórios e executivos.

Na realidade, a participação do Estado na sociedade como consequência da democracia social, contraposta à figura do juiz do direito liberal, intensificou a participação do magistrado nas causas, a fim de legitimar o processo como um todo. 
De acordo com Marinoni, Arenhart e Mitidiero (2015, p. 449) o julgador

[...] não deve mais estar apenas preocupado com o cumprimento das "regras do jogo", cabendo-lhe agora zelar por um processo justo, capaz de permitir: (i) a adequada verificação dos fatos e a participação das partes em um contraditório efetivo, (ii) a justa aplicação das normas de direito material, e (iii) a efetividade da tutela dos direitos, já que a inércia do juiz, ou o abandono do processo à sorte que as partes lhe derem, tornou-se incompatível com a evolução do Estado e do direito.

Ressalta-se, por outro lado, que

[...] a atividade da Jurisdição é substitutiva. Ao regular o caso concreto, ou dando efetivação ao que já está devidamente acertado, o juiz faz o que deveriam fazer as partes: a autocomposição do litígio, ou a realização voluntária das obrigações. Tanto o litígio quanto a insatisfação do direito são fenômenos que se revelam no processo. O juiz não sai à cata de controvérsias sociais nem de obrigações não cumpridas, para lhes aplicar a devida solução ou cumprimento. As questões devem chegar ao processo e, neste caso, só atingem tais fins quando a parte toma a iniciativa de fazê-lo. (SANTOS, 1994, p. 286).

Verifica-se, portanto, que o juiz não dá início à relação processual, mas pode, no exercício de seu poder jurisdicional, amparado no art. $2^{\circ}$ do Código de Processo Civil, que prevê que "o processo começa por iniciativa da parte e se desenvolve por impulso oficial, salvo as exceções previstas em lei”, forçar "[...] as partes à prática de atos essenciais do processo ou a ele dar andamento com consequências específicas, quando os interessados deixarem de executar aqueles de seu exclusivo interesse" (SANTOS, 1994, p. 287).

A "missão social" conferida aos magistrados encontra respaldo na legislação processual civil vigente, no que tange, por exemplo, à possibilidade de determinação ex officio das provas necessárias ao julgamento do mérito (art. 370 do Código de Processo 
Civil) e à previsão constante do art. 297 do codex de processo de 2015 , que dispõe que "o juiz poderá determinar as medidas que considerar adequadas para efetivação da tutela provisória".

Pode-se afirmar, portanto, que a função jurisdicional

[...] transcende a modesta e subserviente atividade de aquiescer aos caprichos e à vontade do legislador, porquanto como poder criador, o juiz não constitui um simples técnico que mecanicamente aplica o direito em face de litígios reais. Busca, em verdade, solucionar os conflitos de interesse entre sujeitos individuais e coletivos, operando juridicamente como uma verdadeira força de expressão social que se define pelo exercício de uma função capaz de explorar as fissuras, as antinomias e as contradições da ordem jurídica. O magistrado, por conseguinte, não se limita à atividade de natureza meramente interpretativa ou dedutiva daquilo que lhe é dado. Sua tarefa versa na revelação de uma forma jurídica mais adequada, mais equânime e mais justa. (ABREU, 2011, p. 311).

Isso porque, de acordo com Abreu (2011, p. 313), o magistrado tem o dever fundamental de fazer justiça, afastando-se, para tanto, de mecanismos estéreis que cerceiem sua liberdade de decisão para o caso concreto, impendendo, assim, seu papel institucional de construir uma ordem jurídica justa e comprometida com valores e princípios éticos e sociais que devem ser preservados pela sociedade.

Vê-se, então, que o papel do magistrado transcende o de mero expectador na relação jurídico-processual civil, pois há hipóteses em que detém o poder-dever de agir visando à realização da justiça e proteção do bem da vida que se pretende resguardar por meio da lide mesmo que, para tanto, tenha que determinar a medidas não expressamente requeridas pela parte.

\subsection{O sequestro de verbas públicas como meio de assegurar o cumprimento de decisão que compele os entes públicos ao fornecimento de medicamentos}

Como já mencionado, o art. 297 do Código de Processo Ci- 
vil dispõe que "o juiz poderá determinar as medidas que considerar adequadas para a efetivação da tutela provisória".

Em sentido semelhante, o art. 536 do mesmo diploma legal, ao tratar do cumprimento de sentença que reconhece a exigibilidade de obrigação de fazer ou não fazer, prevê que "o juiz poderá, de ofício ou a requerimento, para a efetivação da tutela específica ou a obtenção da tutela pelo resultado prático equivalente, determinar as medidas necessárias à satisfação do exequente".

Denota-se, da leitura dos artigos legais acima elencados, que "[...] comprometido com a efetividade, para a realização da tutela provisória, o novo CPC autoriza o juiz a determinar as medidas que considerar adequadas" (IMHOF, 2016, p. 473). Da mesma forma, no que concerne ao cumprimento de sentença, Medina (2015, p. 854) afirma que

[...] não sendo o caso de se tentar a obtenção de tutela específica, deve o órgão jurisdicional atuar no sentido de de obter resultado prático equivalente. A realização de medidas tendentes a propiciar ao demandante uma situação equiparável àquela que decorreria do cumprimento da obrigação pelo réu não encontra maiores obstáculos [...] (grifo do autor).

Trata-se, em verdade, de forma de "solucionar", tanto em sede de tutela de urgência quanto em execução de sentença, o descumprimento de comando judicial, possibilitando à parte requerente auferir resultado prático equivalente àquele originalmente buscado na demanda.

A possibilidade de o magistrado ordenar a execução das medidas que julgar adequadas à efetivação da tutela pretendida encontra respaldo no fato de que

[...] as decisões dos juízes devem inspirar-se no princípio da razoabilidade e no critério de discricionariedade. Os poderes jurisdicionais do juiz estão estruturados sobre estas duas colunas. Deste modo, a enunciação dos poderes do juiz não prescinde da análise destes elementos. 
O processo deve ter "feição humana" de maneira que, além da participação do juiz no correto exercício da jurisdição, sejam compatibilizados os valores correspondentes aos grandes princípios constitucionais do processo, a saber o contraditório e a igualdade das partes.

Contudo, não basta a observância a estes princípios, exigindo-se do juiz a adoção de critérios de julgamento e da justiça das decisões. No momento valorativo da decisão cumpre ao órgão julgador atentar para os sentimentos sociais de justiça predominantes e realizar a interpretação razoável do texto legal e da prova produzida, no sentido de propiciar aos litigantes e à sociedade a satisfação de sua aspiração de justiça. (MARTINS, 2004, p. 132).

Ainda segundo Martins (2004, p. 138),

[...] a interpretação da lei pelo juiz deve ser de modo a levar à conclusão mais justa para a resolução do problema submetido à sua jurisdição. Desta maneira, o juiz, ao invés de desobedecer a ordem jurídica positiva, está de fato dando a ela o mais perfeito cumprimento eis que o legislador quando emite as normas gerais se propõe a alcançar do melhor modo possível a realização da justiça e de seus valores numa determinada sociedade concreta.

Se a intenção do sistema do Direito positivo é realizar este desiderato ao juiz cumpre interpretar as leis de maneira que o resultado de sua aplicação nos casos singulares constitua a realização do maior grau de justiça de conformidade com a proposição do legislador.

Vislumbra-se, desse modo, que no cenário do processo civil contemporâneo, tanto em sede de tutela de urgência quanto em cumprimento de sentença, busca-se primordialmente a satisfação do direito do autor, competindo ao juiz, como representante do Estado e em atenção aos critérios teleológicos de interpretação da lei, determinar a execução de medidas eficazes à garantia de resultado prático equivalente ao adimplemento da obrigação, a fim de viabilizar a realização da verdadeira justiça.

Para atender aos anseios das partes e de resguardar a efetividade das decisões judiciais nos processos que envolvem a 
concessão de medicamentos pelo Estado a particulares, é praxe a cominação de "penalidades" voltadas a assegurar o resultado prático visado na demanda, qual seja, a entrega do tratamento médico pleiteado.

Assim, com vistas a resguardar a mencionada efetividade, no ano de 2010, Supremo Tribunal Federal reconheceu a existência de repercussão geral no que concerne à possibilidade de determinação de sequestro de verba pública para garantir o cumprimento de decisão judicial que determina o fornecimento de medicamentos - Tema n. 289 -, ainda pendente de julgamento.

A Ministra Ellen Gracie, então relatora do recurso, entendeu pela existência de repercussão geral no que tange à matéria, com finalidade de ratificar entendimento já pacificado pela Corte Suprema, nos seguintes termos:

A questão versada no presente apelo extremo possui relevância do ponto de vista econômico, político, social e jurídico, nos termos do $\S 1^{\circ}$ do art. 543-A do Código de Processo Civil [de 1973]. É que o assunto interfere nas receitas públicas, alcançando, certamente, grande número de interessados.

Ressalte-se que, com o reconhecimento da existência de repercussão geral da matéria, deve ser aplicado o regime legal previsto no art. 543-B do Código de Processo Civil [de 1973], conforme procedimento já apreciado por esta Corte no julgamento das Questões de Ordem no RE 579.431, no RE 580.108 e no RE 582.650, todos de minha relatoria.

Ademais, verifico que a matéria já se encontra pacificada no âmbito desta Corte, no sentido da possibilidade do bloqueio de verbas públicas para garantir o fornecimento de medicamentos $[\ldots]$.

Desse modo, entendo que, com o reconhecimento da existência de repercussão geral e havendo entendimento consolidado da matéria, os Tribunais de origem e as Turmas Recursais podem, desde logo, com fundamento no $\S 3^{\circ}$ do citado art. 543-B, aplicar a citada orientação anteriormente 
firmada por este Supremo Tribunal Federal.

Igualmente, dada a pacificação de entendimento, entendo não ser necessária a apreciação pelo Plenário desta Corte, possibilitando o julgamento monocrático deste recurso, nos termos do art. 325, caput, do RISTF, e, ainda, a aplicação dessa orientação pelos tribunais de origem.

4. Ante o exposto, manifesto-me pela ratificação da jurisprudência deste Tribunal sobre o assunto discutido no presente recurso extraordinário e pela existência de repercussão geral da matéria, a fim de que sejam observadas as disposições do art. 543-B do Código de Processo Civil [de 1973] (BRASIL, 2010 - grifos do autor).

Da leitura da decisão, verifica-se que a matéria atinente à possibilidade de bloqueio de verbas para garantir o fornecimento de medicamentos encontra-se pacificada no âmbito do Supremo Tribunal Federal, destinando-se o reconhecimento da repercussão geral apenas à ratificação do entendimento já adotado pela Corte.

Destaca-se, ainda, que o Superior Tribunal de Justiça, por sua vez, quando do julgamento do Tema repetitivo n. 84, entendeu, de igual maneira, que o direito à saúde deve prevalecer sobre a impenhorabilidade dos recursos da Fazenda Pública, facultando, dessa forma, que o magistrado, para garantir o cumprimento da obrigação do Poder Público, determine a medida de sequestro de verbas.

O acórdão do julgamento foi assim ementado:

PROCESSUAL CIVIL. ADMINISTRATIVO. RECURSO ESPECIAL. ADOÇÃO DE MEDIDA NECESSÁRIA À EFETIVAÇÃO DA TUTELA ESPECÍFICA OU À OBTENÇÃO DO RESULTADO PRÁTICO EQUIVALENTE. ART. 461, § 50. DO CPC. BLOQUEIO DE VERBAS PÚBLICAS. POSSIBILIDADE CONFERIDA AO JULGADOR, DE OFÍCIO OU A REQUERIMENTO DA PARTE. RECURSO ESPECIAL PROVIDO. ACÓRDÃO SUBMETIDO AO RITO DO ART. 543-C DO CPC E DA RESOLUÇÃO 08/2008 DO STJ. 
1. Tratando-se de fornecimento de medicamentos, cabe ao Juiz adotar medidas eficazes à efetivação de suas decisões, podendo, se necessário, determinar até mesmo, o sequestro de valores do devedor (bloqueio), segundo o seu prudente arbítrio, e sempre com adequada fundamentação.

2. Recurso Especial provido. Acórdão submetido ao regime do art. 543-C do CPC e da Resolução 08/2008 do STJ (BRASIL, 2013).

Na oportunidade, concluiu-se o seguinte:

É possível ao julgador determinar o bloqueio de verba pública para garantir o cumprimento da obrigação do Poder Público de fornecer medicamentos para portadores de doença grave, havendo nos autos comprovação de que o Estado não esteja cumprindo essa obrigação, sobretudo quando a desídia do ente estatal implicar grave lesão à saúde ou mesmo risco à vida do paciente. Isso porque, diante das circunstâncias do caso concreto, cabe ao magistrado aferir o modo mais adequado para tornar efetiva a tutela, tendo em vista o fim da norma. Não se deve olvidar, também, a prevalência da tutela ao direito subjetivo à saúde sobre o interesse público, que, no caso, consubstancia-se na preservação da saúde em detrimento dos princípios do Direito Financeiro ou Administrativo. Deve-se concluir que, em situações de inconciliável conflito entre o direito fundamental à saúde e o da impenhorabilidade dos recursos da Fazenda Pública, prevalece o primeiro sobre o segundo. (BRASIL, 2013).

Na mesma esteira, o Tribunal de Justiça do Estado de Santa Catarina, por meio do Grupo de Câmaras de Direito Público, aprovou o seguinte enunciado:

ENUNCIADO N. IX. Ao conceder a tutela provisória, em ação voltada para concessão de medicamentos, o magistrado fixará prazo razoável para o cumprimento da medida, sob pena de sequestro de quantia necessária à efetivação do comando judicial, afastada a imposição de multa. (SANTA CATARINA, 2016).

A jurisprudência da Corte Catarinense há muito é firme no sentido de que 
[...] é possível a imposição do bloqueio de verbas públicas para garantir o fornecimento de medicamentos pelo Estado (genericamente falando) portador de doença grave, como medida executiva (coercitiva) para a efetivação da tutela, ainda que em caráter excepcional, com o objetivo de assegurar o cumprimento da obrigação de fazer, eis que o legislador deixou ao arbítrio do Juiz a escolha das medidas que melhor se harmonizem às peculiaridades de cada caso concreto (CPC, art. 461, $\S 5^{\circ}$ ). Portanto, em caso de comprovada urgência, é possível a aquisição, mediante sequestro de verba pública, de medicamento necessário a manutenção da saúde de pessoa carente de recursos para adquiri-lo, sendo inaplicável o regime especial dos precatórios $(\mathrm{CF}$, art. 100), utilizado nas hipóteses de execução de condenações judiciais contra a Fazenda Pública, pois, na espécie, deve ser privilegiada a proteção ao direito à vida e à saúde do paciente. (SANTA CATARINA, 2009).

Tal entendimento decorre do fato de que

[...] a imposição de bloqueio ou sequestro de verbas públicas apresenta-se mais apta a garantir o cumprimento da determinação judicial de fornecimento de medicamentos pelo Poder Público, na medida em que, mesmo não atendido o comando sentencial, o sequestro dos valores será suficiente para agasalhar a pretensão do enfermo em garantir, de forma eficaz, o seu direito à saúde, enquanto que a multa cominatória raramente atingirá a finalidade da decisão judicial, senão por vontade do próprio demandado. (SANTA CATARINA, 2016).

Portanto, observa-se que, com amparo no diploma processual civil vigente e nas orientações jurisprudenciais emanadas tanto dos Tribunais Superiores quanto de Corte Estadual, é perfeitamente possível ao magistrado ordenar o sequestro de valores das contas do Poder Público a fim de assegurar o cumprimento de decisão judicial que o compele ao fornecimento de medicamentos, tendo em vista que, em exercício de ponderação, o direito à saúde deve prevalecer sobre a impenhorabilidade dos recursos públicos. 


\section{CONCLUSÃO}

Por meio do presente estudo, verificou-se que o direito fundamental à saúde merece especial proteção do Estado, tendo em vista a existência de previsão expressa nesse sentido, contida no art. 196 da Constituição da República Federativa do Brasil de 1988. Evidenciou-se, ainda, que tal disposição contempla um caráter dúplice: a saúde como direito fundamental do cidadão e como dever do Poder Público, que deve resguardá-la, promovê-la e recuperá-la, por meio da implantação de políticas sociais e econômicas destinadas à redução do risco de doenças e de outros agravos, mediante acesso universal e igualitário.

Ocorre, todavia, que as políticas públicas atualmente implantadas mostram-se, por vezes, insuficientes para o fornecimento de medicamentos necessários ao tratamento de saúde dos cidadãos, seja porque não estão contemplados nas listas padronizadas do Sistema Único de Saúde, seja porque o paciente não preenche os requisitos específicos estabelecidos nos protocolos criados para a concessão dos fármacos e/ou serviços.

Diante da negativa administrativa ou da recalcitrância do Poder Público, inúmeras ações são judicializadas buscando compelir os entes federativos à concessão dos medicamentos almejados pela parte. Nesses casos, tanto em sede de tutela de urgência quanto em cumprimento de sentença, é comum que o magistrado, ao deferir o pedido de fornecimento do fármaco, comine penalidade em caso de descumprimento da ordem pelo ente público requerido.

A fim de dar efetividade ao provimento jurisdicional, entende-se que a maneira mais eficaz de garantir a entrega do bem da vida pleiteado pelo autor é o sequestro de verbas públicas, uma vez que, diferentemente do que ocorre no caso de cominação de multa, o medicamento será efetiva e tempestivamente disponibilizado à parte, que, uma vez transferido o valor 
correspondente ao custo do medicamento, poderá adquiri-lo pela via particular.

Oportuno mencionar que os Tribunais Superiores e o Tribunal de Justiça do Estado de Santa Catarina vêm, há muito, entendendo que tal medida se mostra mais adequada à consecução do objetivo visado com o ajuizamento da demanda, qual seja, o direito à saúde e, em última análise, o próprio direito à vida.

Conclui-se, assim, que a medida correta a ser adotada pelo magistrado, a fim de assegurar o cumprimento de decisão que compele o Poder Público ao fornecimento de medicamentos, é a determinação de sequestro de verbas, a fim de garantir a concretização do direito fundamental à saúde.

\section{REFERÊNCIAS}

ABREU, Pedro Manoel. Processo e democracia: o processo jurisdicional como um locus da democracia participativa e da cidadania inclusiva no estado democrático de direito. São Paulo: Conceito Editorial, 2011.

ASENSI, Felipe Dutra. Direito à saúde: práticas sociais reivindicatórias e sua efetivação. Curitiba: Juruá, 2013.

BRASIL. Lei n. 13.105, de 16 de março de 2015. Código de processo civil. Disponível em: <www.planalto.gov.br> Acesso em: 10 maio 2016.

BRASIL. Constituição (1988). Constituição da República Federativa do Brasil, de 5 de outubro de 1988. Disponível em <www.planalto.gov.br> Acesso em: 4 out. 2016.

BRASIL. Supremo Tribunal Federal. Recurso extraordinário n. 607582, Rel. Min. Ellen Gracie, j. 13 ago. 2010. Disponível em <www.stf.jus.br>. Acesso em: 7 out. 2016.

BRASIL. Supremo Tribunal Federal. Agravo regimental na suspensão de tutela antecipada $n^{\circ}$ 175, Rel. Min. Gilmar Mendes, j. 17 mar. 2010. Disponível em: <www.stf. jus.br>. Acesso em: 7 out. 2016.

BRASIL. Supremo Tribunal Federal. Recurso extraordinário n. 241.630, Rel. Min. Celso de Mello, j. 7 mar. 2001. Disponível em: <www.stf.jus.br>. Acesso em: 07 out. 2016.

BRASIL. Supremo Tribunal Federal. Agravo regimental no recurso extraordinário com agravo n. 947823, Rel. Min. Edson Fachin, j. 28 jun. 2016. Disponível em: <www. stf.jus.br>. Acesso em: 7 out. 2016.

BRASIL. Superior Tribunal de Justiça. Recurso especial n. 1069810/RS, Rel. Min. Napoleão Nunes Maia Filho, j. 23 out. 2013. Disponível em: <www.stj.jus.br>. Acesso em: 10 out. 2016.

CANUT, Letícia. Estado democrático de direito, políticas públicas e direito à saúde: 
uma breve introdução sobre o SUS. In: VIEIRA, Reginaldo de Souza; CERETTA, Luciane Besognin. Temas em direito sanitário \& saúde coletiva: SUS - uma política de Estado. Criciúma: UNESC, 2013, p. 13-28.

CINTRA, Antonio Carlos de Araujo; DINAMARCO, Cândido Rangel; GRINOVER, Ada Pellegrini. Teoria geral do processo. 4. ed. São Paulo: Revista dos Tribunais, 1984.

CUNHA JÚNIOR, Dirley da. Curso de direito constitucional. 10. ed. Salvador: JusPODIVM, 2016.

IMHOF, Cristiano. Novo código de processo civil comentado. 2. ed. São Paulo: BookLaw, 2016.

MARINONI, Luiz Guilherme; ARENHART, Sérgio Cruz; MITIDIERO, Daniel. Novo curso de processo civil: teoria do processo civil. São Paulo: Revista dos Tribunais, 2015.

. Novo curso de processo civil: tutela dos direitos mediante procedimento comum. São Paulo: Revista dos Tribunais, 2015.

MARTINS, Nelson Juliano Schaefer. Poderes do juiz no processo civil. São Paulo: Dialética, 2004.

MEDINA, José Miguel Garcia. Novo Código de Processo Civil comentado: com remissões e notas comparativas ao CPC/1973. São Paulo: Revista dos Tribunais, 2015.

MENDES, Gilmar Ferreira; BRANCO, Paulo Gustavo Gonet. Curso de direito constitucional. 10. ed. São Paulo: Saraiva, 2015.

PEREIRA, Hélio do Valle. Manual de direito processual civil: Roteiros de Aula - Processo de Conhecimento. 2. ed. Florianópolis: Conceito Editorial, 2008.

SANTOS, Ernane Fidélis dos. Manual de direito processual civil. 3. ed. São Paulo: Saraiva, 1994. v. 2.

SARLET, Ingo Wolfgang. A eficácia dos direitos fundamentais: uma teoria geral dos direitos fundamentais na perspectiva constitucional. 12. ed. Porto Alegre: Livraria do Advogado, 2015.

SARLET, Ingo Wolfgang; MARINONI, Luiz Guilherme; MITIDIERO, Daniel. Curso de direito constitucional. São Paulo: Revista dos Tribunais, 2012.

SANTA CATARINA. Grupo de Câmaras de Direito Público. Enunciado n. IX. Diário da Justiça Eletrônico. n. 2355.

SANTA CATARINA. Tribunal de Justiça. Agravo de Instrumento n. 2009.051278-4, Rel. Des. Jaime Ramos, j. 12 nov. 2009. Disponível em: <www.tjsc.jus.br>. Acesso em: 11 out. 2016.

SANTA CATARINA. Tribunal de Justiça. Apelação cível n. 000563553.2010.8.24.0135, Rel. Des. Francisco Oliveira Neto, j. 27 set. 2016. Disponível em: <www.tjsc.jus.br>. Acesso em: 11 out. 2016.

SILVA, José Afonso da apud CUNHA JÚNIOR, Dirley da. Curso de direito constitucional. 10. ed. Salvador: JusPODIVM, 2016.

Artigo recebido em: 25/04/2017

Artigo aprovado em: 02/10/2017 